Bol. Acad. peru. leng. 56. 2013 (123-145)

\title{
GONZALO PIZARRO, ¿LA PRIMERA NOVELA \\ HISTÓRICA DEL PERÚ REPUBLICANO \\ O UN DRAMA FRUSTRADO DE SEGURA?
}

\author{
Alberto Varillas Montenegro \\ Academia Peruana de la Lengua
}

Fecha de recepción:

$11 / 10 / 2013$

Fecha de aceptación:

$28 / 10 / 2013$

\section{PRESENTACIÓN}

La literatura peruana del siglo XIX ha merecido pocos estudios rigurosos y buena parte de ellos han aparecido recién en las últimas décadas. Es posible ilustrar lo dicho con el caso de nuestro Costumbrismo, pues hasta que Maida Watson le dedicara en 1980 su valioso ensayo sobre el cuadro de costumbres, no había merecido sino algunos estudios breves, mayormente de carácter biográfico, y comentarios aparecidos dentro de las historias del Perú y de su literatura ${ }^{1}$. El presente trabajo versa sobre Gonzalo Pizarro (novela cuyo autor, Manuel Ascensio Segura, es precisamente uno de los más importantes escritores costumbristas peruanos), y pretende determinar si se trata de una novela concebida como tal hacia 1843 o principios de 1844 o si fue preparada algunos años

1 Maida Watson E. El cuadro de costumbres en el Perú decimonónico. Lima, Fondo Editorial de la Pontificia Universidad Católica del Perú, 1980. 
antes como un drama que Segura archivó pues acababa de fracasar con otras dos obras suyas, ambas de tema histórico, para teatro. ${ }^{2}$

\section{ANTECEDENTES}

\section{Gonzalo Pizarro: el texto y la paternidad}

El diario El Comercio de Lima publicó, entre el 13 y el 20 de mayo de 1844, al pie de sus primeras páginas y revistiendo la modalidad de folletín, la novela titulada Gonzalo Pizarro ${ }^{3}$. Recién en la sexta y última entrega, el autor reveló su identidad al suscribir el texto con las iniciales $\mathrm{M}$ [anuel] A[scensio] S[egura]. Ciento sesenta años después, en el 2004, Ricardo Silva Santisteban preparó la segunda edición de la novela que apareció precedida de una breve Presentación ${ }^{4}$; la tercera edición de Gonzalo Pizarro corresponde al año siguiente (2005) y forma parte de las Obras completas de Segura preparada por el autor de estas líneas por encargo de la Escuela Profesional de Ciencias de la Comunicación de la Universidad de San Martín de Porres'. No se conoce otra versión de la novela ni se tiene registrada reproducción parcial alguna de su texto.

Es posible que Gonzalo Pizarro haya constituido material de interés para el público de aquellos años, como seguramente ocurría con buena parte de los folletines que publicaban tanto El Comercio (aparecido en mayo de 1839) como La Bolsa (a partir de enero de 1841). Ambos diarios reproducían con gran frecuencia novelas, relatos, historias breves y otros textos que podían asimilar el formato de folletín; este era un mecanismo por el que los periódicos aseguraban la fidelidad de sus lectores.

2 El asunto fue planteado por el autor de estas líneas en el año 2005 al publicar las Obras completas de Segura (tomo II, pp. 823-824).

3 Manuel A. Segura, Gonzalo Pizarro. [En:] El Comercio. Lima, 13 (pp.1-2), 14 (pp. 1-2), 15 (pp. 1-2), 17 (pp. 1-2), 18 (pp. 1-3) y 20 (pp. 1-3) de mayo de 1844.

4 Manuel Ascensio Segura. Gonzalo Pizarro. Edición y presentación de Ricardo Silva-Santisteban. Lima, Editorial Universitaria de la Universidad Ricardo Palma, 2004.

5 Manuel Ascensio Segura. Obras completas. Edición, introducción y notas de Alberto Varillas Montenegro. Lima, Escuela Profesional de Ciencias de la Comunicación de la Universidad de San Martín de Porres, 2005. El texto de la novela aparece en el tomo 2, pp. 827-857; el estudio sobre la misma, en las pp. 819-825. 
El primero en atribuir la autoría de Gonzalo Pizarro a Segura fue Ricardo Palma. Esta se encuentra en el Preámbulo biográfico y noticiero que el tradicionista preparó, más de cuarenta años después (1885), al prologar la edición de las Obras completas del comediógrafo limeño:

Fundado en 1839 el diario "Comercio" [...] Segura colaboró en él activamente y producción suya es, entre otras que engalanan las columnas de ese periódico, una novelita, Gonzalo Pizarro, que ocupó durante varios días la columna del folletín, y a la que no damos más significación que la debida a un lijero ensayo en ese género literario 6 .

En 1914, setenta años después de la primera edición, Eduardo Garland Roel, en una tesis universitaria, recuerda que Segura colaboró en El Comercio “...publicando una novela llamada 'Gonzalo Pizarro', que no debemos considerar sino como un mero ensayo del joven escritor" 7 . Desde ese año, Gonzalo Pizarro no aparece registrada en los textos de historia de la literatura peruana, aunque Luis Alberto Sánchez le dedica un breve comentario en El señor Segura, hombre de teatro:

En "El Comercio" se insertaría una novela histórica debida a su pluma bajo el título de "Gonzalo Pizarro", en donde el estilo del autor apenas alcanza mediana altura expresiva y nula capacidad investigatoria ${ }^{8}$.

Elsa Villanueva se limita a mencionarla en $1969^{\circ}$. El autor de estas líneas se ha ocupado del asunto en dos ocasiones: 1964 y 1992. En 1964 recordaba que

6 Manuel Ascensio Segura. Artículos, poesías y comedias de ... Lima, Carlos Prince, (impresor y librero-editor), 1886.

7 Eduardo Garland Roel. Manuel Ascensio Segura, sus comedias, artículos y poesías. Lima, Biblioteca de la Revista Universitaria, Apéndice del vol. $2^{\circ}$ del año IX, 1914, p. 4.

8 Luis Alberto Sánchez. El señor Segura, hombre de teatro. Lima, Editorial PTCM, 1947, p. 48. En la segunda edición de esta obra (1976), Sánchez no modifica el comentario.

9 Elsa Villanueva de Puccinelli. Bibliografía de la novela peruana. Lima, Ediciones de la Biblioteca Universitaria, 1969, p. 88. La referencia aparece en el Apéndice y con fecha 1839 .

Bol. Acad. peru. leng. 56(56), 2013 
En El Comercio decide Segura publicar su único esfuerzo en el campo de la novela, Gonzalo Pizarro. [...] Esta obra, de tipo histórico, desarrolla temas que Segura no conocía bien pero que, presentados alrededor del violento hermano del fundador de Lima y ambientados en los épicos años de la Conquista, le permiten esbozar un argumento de tipo folletinesco ${ }^{10}$.

\section{La producción literaria inicial de Segura}

En la vida de Segura (1805-1872) hay varios momentos oscuros. Casi nada se sabe de él hasta fines de 1824 cuando participa en la batalla de Ayacucho junto con su padre, integrando las fuerzas realistas; tampoco se sabe mucho de sus quehaceres de los años siguientes. Entre 1825 y 1832 forma parte del Ejército peruano, institución en la que llega a obtener el grado de mayor ${ }^{11}$; es posible que entre 1832 y principios de 1835 haya radicado en Arequipa, donde pudo haber redactado el drama $\mathrm{La}$ Pepa, ambientado en esa ciudad; a partir de junio de 1835 se desempeña, durante unos pocos meses, como Administrador de la Aduana de Huacho; participa en la batalla de Socabaya en la que el general Salaverry fue vencido y fusilado por las fuerzas de la futura Confederación Perúboliviana al mando del general Santa Cruz (18 de febrero de 1836). Segura, que sobrevivió al combate, logra escapar y emprende el camino hacia el norte, posiblemente con el propósito de esconderse en la sierra de Ayacucho, en la cual tenía familiares cercanos y una propiedad en condominio; sin embargo, a medio camino fue capturado en Camaná por las fuerzas del nuevo Gobierno ${ }^{12}$. Se desconoce cuánto tiempo estuvo detenido nuestro escritor pero la consolidación del régimen confederado fue tan rápida que es posible que, tal como ocurrió con otros prisioneros,

10 Alberto Varillas M. Felipe Pardo y Aliaga. Manuel Ascensio Segura. Lima, Biblioteca Hombres del Perú, 1964, pp. 58-59. Años después, Varillas también menciona a Gonzalo Pizarro entre las novelas peruanas de esa época recogidas en El Comercio (Alberto Varillas M. La literatura peruana del siglo XIX. Periodificación y caracterización. Lima, Fondo Editorial de la Pontificia Universidad Católica del Perú, 1992, p. 237).

11 Parte de esta información está tomada de Manuel Zanutelli Rosas. Periodistas peruanos del siglo XIX. Lima, Escuela Profesional de Ciencias de la Comunicación de la Universidad de San Martín de Porres, 2005, pp. 335-339.

12 Su captura se anuncia en el periódico oficial El Redactor Peruano en Lima el 26 de febrero de 1836. 
haya sido puesto en libertad con alguna rapidez (¿semanas? ¿meses?) y que nuevamente haya enrumbado hacia la sierra ayacuchana donde debe de haber permanecido hasta el fin del régimen confederado ${ }^{13}$. Derrotado Santa Cruz y disuelta la Confederación después de la batalla de Yungay (enero de 1839), nuestro escritor debe de haber viajado a la capital después de disfrutar por más de dos años y medio del bucólico paisaje de la serranía ayacuchana.

No puede dudarse que durante el largo período en que se encontró alejado de Lima, Segura probablemente llevó a cabo alguna actividad rentada. Pero, además, suponemos que pudo disponer de buenas oportunidades para leer y escribir. Y con el tiempo del que debe haber dispuesto y con la experiencia que acababa de adquirir mediante la reciente redacción de La Pepa bien pudo haber aprovechado sus ratos de ocio preparando - íntegras o en parte- la primera de sus obras teatrales, Amor y política, y sus únicos tres dramas que no están ambientados necesariamente en Lima: Blasco Núñez de Vela, Gonzalo Pizarro y La Espía ${ }^{14}$. Estas tres obras son, curiosamente, las únicas de su autoría que tienen carácter histórico, lo que obliga a tener presente su apego por esa temática durante aquel tiempo.

Se ha indicado que, durante su estancia en Ayacucho (1836-1838/9), Segura dispuso de un buen tiempo libre; a la inversa, se puede suponer que anduvo falto del mismo entre los años siguientes (1839 y 1844) puesto que durante ellos prepara la parte más voluminosa de su obra ${ }^{15}$. Durante esos cinco años, redacta 9 de sus 16 obras teatrales (aunque en este grupo no

13 Debe recordarse que en 1824 tanto Segura como su padre participaron con las fuerzas realistas en la batalla de Ayacucho y que, después del triunfo patriota, ambos permanecen durante un tiempo en aquella región. Es posible que hayan vivido en o cerca del pueblo de Ocros, lugar de relativa importancia en la ruta Cuzco-Ayacucho, y que de la estadía en este lugar haya tomado nuestro escritor el telón de fondo para La espía, drama que podría calificarse como histórico. Por ello, no debe extrañar si en esta ocasión en que su vida volvío a correr peligro, Segura haya regresado a la región de Ayacucho, concretamente a Ocros, donde su familia era propietaria del fundo Parco Chico.

14 También pudo haber redactado $E l$ sargento Canuto, comedia que se estrena en septiembre de 1839.

15 No se considera en esos años a La Pepa, comedia de 1834-1835, que nunca ha sido representada. 
esté comprendido lo más valioso de su teatro), la totalidad de sus cuadros de costumbres (40) y 18 de sus 21 poesías. Además, lleva adelante una destacada labor periodística como redactor de El Comercio, director de La Bolsa y propietario y único redactor de El Cometa.

Lo indicado nos permite suponer que en el bienio (quizás trienio) ayacuchano (1836/7-1838/9) Segura dispuso de tiempo para redactar sus tres obras de tema histórico: el drama Blasco Núñez de Vela (1839), la novela Gonzalo Pizarro (1844) y el drama La Espía (1845) ${ }^{16}$. Con algún cuidado también podría añadirse a este grupo el drama o comedia Amor y política (1839), al que Sánchez atribuye el mismo carácter ${ }^{17}$.

\section{Lugar y fecha de redacción de Gonzalo Pizarro}

De lo expuesto se desprende que es muy posible que Segura haya redactado, en Ayacucho o en una zona cercana a esta ciudad, entre mediados de 1836 y fines de 1838 (si es que no empleó parte de 1839), dos obras para teatro de carácter histórico. Estas se titulan Blasco Núñez de Vela y Gonzalo Pizarro; las tramas giran en torno a las vidas del virrey Núñez de Vela y del gobernador Gonzalo Pizarro. La rivalidad de ambos personajes llegó a tal extremo que después de derrotar a Núñez en la batalla de Jaquijaguana, Pizarro ordenó que lo ejecutaran. Lo estrechamente relacionados que se encuentran los dos personajes conduce fácilmente a suponer que las fuentes que utilizó Segura para ambos dramas deben de haber sido las mismas.

No hay duda de que la primera de las obras mencionadas, Blasco Núñez de Vela, fue un drama que subió a las tablas en Lima el 5 de enero de 1840 y que ni su texto fue entregado por Segura para la primera publicación de sus obras en 1858 ni debe de haber tenido especial acogida puesto que no vuelve a presentarse.

16 Es posible que también se pueda considerar como obra de carácter histórico al excelente drama El resignado, de 1855, aunque redactado en circunstancias distintas.

17 Amor y política fue la primera obra de Segura que subió a los escenarios peruanos. Consta que se representó el 12 de septiembre de 1839 y que ya había sido puesta en escena una vez (quizás el 28 de julio). No se registra una tercera presentación de la obra. Mayor información sobre este texto puede encontrarse en las Obras completas de Segura, publicada por la Universidad de San Martín de Porres. 
Sobre la segunda obra, Gonzalo Pizarro, sostenemos que fue redactada como drama, en tiempos muy cercanos a Blasco Núñez de Vela, pero que Segura, al reparar en que ya tenía en su haber dos fracasos escénicos seguidos (Amor y política, antes de septiembre de 1839; Blasco Núñez de Vela, 5 de enero de 1840), optó por archivarla. Y en esa condición pasa perdida algo más de tres años, hasta que el propio autor la rescata y la convierte en la novela de folletín que ahora nos interesa.

\section{Gonzalo Pizarro, inovela histórica?}

El hecho de que hasta avanzado el siglo XX todos hayan considerado que El padre Horán, de Narciso Aréstegui (1848), era la novela más antigua del Perú republicano, confirma que hasta el siglo XXI nadie había estudiado Gonzalo Pizarro con detenimiento. Este hecho nos obliga a extendernos en las presentes consideraciones ${ }^{18}$.

Al editar Gonzalo Pizarro, Silva Santisteban es enfático al considerar que la obra de Segura "[...] es una manifestación del género novelístico creado por el Romanticismo: la novela histórica" ${ }^{19}$. Casi al mismo tiempo, Marcel Velásquez considera que la publicación de Gonzalo Pizarro en El Comercio

[...] constituye la culminación de los primeros intentos modernos narrativos en nuestra tradición y, por ello, el verdadero inicio de la novela histórica en el Perú. Esta novela de folletín [...] ofrece una visión conflictiva del período de la Conquista y del pasado virreinal ${ }^{20}$.

No es posible enervar el carácter de novela histórica de Gonzalo Pizarro; sin embargo, conviene formular algunas precisiones. Las definiciones de novela histórica propiamente dicha que han merecido mayor aceptación suelen considerar que esta se trata de una subespecie de la novela en la que se recrea un período determinado y en la que

18 Narciso Aréstegui. El padre Horán. (Escenas de la vida del Cuzco). Lima, Imp. de El Comercio, por J. M. Monterola, 1848.

19 Silva Santisteban, op.cit., p. 9.

20 Marcel Velásquez Castro. "Los orígenes de la novela en el Perú: folletín, prensa y romanticismo". En: Ajos y Zafiros. Revista de Literatura. N. ${ }^{\circ}$ 6. Lima, 2004, p. 33. 
forman parte de la acción personajes y eventos no necesaria ni totalmente ficticios. Silva Santisteban enfatiza su aprecio por el género: "No debe olvidarse que muchas obras históricas son relatos extraordinarios y, en muchos de ellos, se utilizó [...] un lenguaje artístico que ha llevado a muchos a considerarlas a la par que las obras de imaginación”.

Sin embargo, a diferencia del modelo creado treinta años antes por Walter Scott con Waverly (1814), en Gonzalo Pizarro Segura no enfrenta la necesidad de añadir personajes ni eventos inexistentes ni la de presentar situaciones extraordinarias sino que se limita, tal como se verá más adelante, a dar forma de novela a hechos tomados de cuando menos las historias de la conquista del Perú de Gómara y de Herrera, empleando sin duda el marco de la Historia general del Perú del Inca Garcilaso de la Vega, que es posterior a ambas.

\section{El argumento de la novela}

La novela/folletín Gonzalo Pizarro está dividida en seis partes (¿capítulos?) de extensión más o menos comparables, carentes de título, señaladas únicamente con números romanos. El argumento de la novela es el siguiente:

I.

En una noche de marzo de 1547 , se encontraban reunidos en la casa del licenciado Diego Cepeda el indebidamente proclamado Gobernador del Perú, Gonzalo Pizarro; el maese de campo de sus tropas Francisco de Carbajal; y el dueño de casa. En medio del desorden político de la época, Pizarro había usurpado el gobierno después de haber vencido al virrey Blasco Núñez de Vela, a quien dio muerte después de su derrota en la batalla de Añaquito o Iñaquito (enero de 1846); la temerosa Audiencia de Lima ya lo había nombrado gobernador un año antes (noviembre de 1544). En la reunión, Cepeda, quien en su condición de Oidor más antiguo había llegado a encabezar la primera Audiencia de $\mathrm{Lima}^{21}$, traidor

21 Cepeda ejerció la presidencia de la Audiencia de Lima, en su condición de Oidor más antiguo, entre el 17 de septiembre y el 21 de noviembre de 1544 . 
recurrente que por entonces se proclamaba fiel a Pizarro, pretendía forzar a Carbajal a firmar una sentencia de muerte contra el nuevo Presidente de la Audiencia, el pacificador don Pedro de la Gasca, y los integrantes de su Gobierno que se encontraba legalmente constituido. De esta manera, ni Gonzalo ni Carbajal podrían salvar sus vidas si el ejército pizarrista era derrotado. El terrible maese de campo Carbajal, conocido como el Demonio de los Andes, se reía de las amenazas y se negaba a suscribir el documento pues se ufanaba de poder ajusticiar a cualquiera sin trámite alguno, lo que en verdad hace a lo largo de la novela. Agotada la discusión, Pizarro y Carbajal se retiran y Cepeda queda solo tratando de urdir un mecanismo que le permitiera vengarse de ellos.

\section{II.}

La conversación de la escena anterior había sido escuchada tras una puerta por doña María Calderón, antes amante de Pizarro y ahora de Cepeda, y comadre de Carbajal. María era una mujer temperamental y descontrolada, que desde su rompimiento con Pizarro sentía un odio irreprimible contra él; y se le había advertido en repetidas ocasiones que no podía expresarse en términos tan agraviantes contra su antiguo amante, tal como lo hacía constantemente.

En la segunda parte del capítulo, Cepeda y María encargan a Hernán Calderón, hermano de María, que viaje al norte del país. Este debía ubicar a Gasca y asegurarle que su hermana y Cepeda eran leales a la causa del Rey y que con su simulada adhesión a Pizarro solo pretendían ganar su confianza para poder entregarlo a las fuerzas realistas en la primera ocasión en que fuera posible.

\section{III.}

El tercer capítulo se desarrolla en el campamento que Pizarro había establecido en La Legua, punto intermedio entre Lima y el Callao. Una patrulla pizarrista que había capturado a Hernán Calderón cuando se dirigía a Trujillo a buscar a Gasca para poder cumplir con el encargo de Cepeda y de María, lo conduce ante 
Gonzalo Pizarro quien, sin advertir de quién se trataba, ordena que lo entreguen a Carbajal para su inmediata ejecución.

En ese momento aparece María Calderón pidiendo clemencia para su hermano y, agotados todos sus recursos, implora de rodillas a Pizarro, en nombre de la Virgen Santísima, que lo perdone. Pizarro, quien era muy devoto de la Virgen María, accede a este último ruego. Sin embargo, esa misma noche, Calderón vuelve a huir con otro soldado que aparentaba ser leal a Pizarro.

IV.

En Lima, Cepeda, enterado de que Calderón había logrado huir, cabalga hacia el campamento de La Legua para reunirse con Pizarro. Este, enceguecido por el poder pero atemorizado por el temor que ambos tenían ante los rumores de que las fuerzas de Gasca crecían en detrimento de las pizarristas, dudaba sobre la actitud que debía tomar. Cepeda seguía intrigando pues su propósito era neutralizar a Carbajal quien gozaba del apoyo de la tropa.

Mientras tanto, Carbajal, al enterarse en La Legua de que Hernán Calderón había logrado escapar, regresa de inmediato a Lima en busca de los desertores, a quienes esperaba encontrar en casa de María Calderón, de la cual acababan de huir. En esa oportunidad, Carbajal advierte a María, con gran tranquilidad pero en términos tremendamente claros, que no iba a tolerar ninguna actitud adicional que pudiera perjudicar a las huestes de Pizarro o que pudiera considerarse un ataque contra el Gobernador.

Vuelto a La Legua, Carbajal se reúne una vez más con Pizarro y Cepeda. Las intrigas de este minaban cada vez más al atribulado Gobernador que iba advirtiendo la forma sostenida en que sus huestes se iban reduciendo.

\section{V.}

Los últimos dos capítulos tienen lugar en el Cuzco, cinco meses después (¿agosto? de 1547). El capítulo V se desarrolla en la casa de Cepeda y la primera parte comprende la conversación entre este y María Calderón en la cual ella confiesa a su amante que "[...] no he perdonado ni perdono medio para desacreditarlos y 
para disminuir sus prosélitos. Vuesamerced sabe muy bien todos los partidarios que he logrado arrancarles y cuántos soldados han desertado de sus filas que han ido a engrosar las de Gasca en fuerza de mis solicitudes". Esta parte comprende, también, la lectura que hace Cepeda de la carta que le había remitido Gasca acusando recibo del compromiso de lealtad de Cepeda para con la causa del Rey, compromiso que había logrado entregarle Hernán Calderón. La segunda parte del capítulo comprende la sorpresiva llegada de Pizarro, quien reprende severamente a María por hacer precisamente lo que ella acababa de confesar a su hermano: Cepeda la defiende con timidez mientras ella, con gran altanería, se enfrenta de igual a igual con Pizarro insinuando que "[...] está próximo su fin"; Pizarro termina advirtiéndole que “[...] antes puede ser que mueran para siempre esa excesiva vanidad, esas locas esperanzas que alientan a vuesamerced". Pizarro se retira abruptamente y parte al galope; María reinicia el diálogo con una gran carcajada mientras Cepeda, que era plenamente consciente del peligro que podían contener las amenazas de Pizarro, le ruega huir y ponerse a salvo, consejo que ella no acepta.

VI.

El capítulo VI también se lleva cabo en el Cuzco y tiene dos partes: la primera se desarrolla en la casa de Carbajal. Se trata de una reunión de este con un grupo de sus amigos, embriagados hasta no poder mantenerse en pie, que celebran los triunfos de Gonzalo Pizarro y de su maese de campo: todos vaticinan el futuro triunfo de los rebeldes y la derrota de las fuerzas leales al Rey.

La segunda parte describe cómo Carbajal, "[...] armado de pies a cabeza", sale a la calle donde se cruza con Cepeda quien le refiere el enfrentamiento que habían sostenido Pizarro y María. Después de confirmar lo ocurrido, noticia que ya se había difundido por toda la ciudad, Carbajal parte en busca de María junto con dos soldados negros que siempre lo acompañaban. La parte final es dramática: Carbajal llega donde María y le advierte que viene a aplicarle la pena de garrote, pero ella cree que es una broma y le pide que se retire; entonces Carbajal hace entrar a los soldados negros y 
les ordena: “[...] mando y requiero a estos soldados etíopes que le aprieten a vuesamerced el gaznate en mi presencia, para que no hable tanto y tan mal de quien no debe". Los negros cumplen con la orden y, antes de retirarse la siniestra comitiva, cuelgan el cadáver de María de una ventana que daba a la calle. Al salir, Carbajal se encuentra con Cepeda y le informa de lo ocurrido: “¿Qué tal, señor licenciado — le dijo, señalándole con la mano el cuerpo cárdeno de doña María-. ¿No le dije a vuesamerced que mi comadre era una santa? Mírela vuesamerced, qué calladita está. Apuesto ciento contra uno a que no vuelve a abrir el pico". Y volviendo las riendas a su mula, se marcha paso a paso dejando al traidor y cobarde Cepeda inmóvil y absorto en su dolor y desesperación.

La novela termina con un extenso párrafo de consideraciones históricas relacionadas con el triunfo de Gasca en la batalla de Sacsahuana o Jaquijahuana, en abril de 1548, y el ajusticiamiento de Pizarro y de Carbajal. Con la desaparición de estos últimos, Cepeda pudo considerarse triunfante; sin embargo, Gasca lo envía a España donde fue condenado a muerte por haber sido en un tiempo partidario de Gonzalo Pizarro. Cepeda se anticipa a la ejecución y logra envenenarse en la cárcel.

\section{Las fuentes de Gonzalo Pizarro}

Resulta imprescindible referirse a las fuentes que empleó Segura para preparar su novela, reiterando que deben de haber sido las mismas que empleó para su drama Blasco Núñez de Vela, y que sin duda fueron las historias de Gómara, Herrera, Garcilaso y Zárate.

El castellano Francisco López de Gómara (1511-1560?) fue autor de la Primera y segunda parte de la historia general de Indias con todo el descubrimiento y cosas notables que han acaecido desde que se ganaron hasta el año 1551, de la cual aparecieron múltiples ediciones en España y Flandes entre 1552 y 1555 . Porras la considera “[...] una de las más elegantes y 
documentadas crónicas del hallazgo del Nuevo Mundo"22. En lo que respecta a la historia peruana, continúa Porras, Gómara, que nunca estuvo en América, tuvo informantes directos y confiables que dan a su crónica un interés especial. Debido a ello, y por la calidad de la información que recoge y por la difusión que tuvo la Historia... de Gómara, desde su aparición, se convirtió en fuente obligada para los historiadores de la hispanoamérica del siglo XVI. Desde mediados del siglo XVIII, la obra de Gómara circulaba profusamente en España y América en la reedición de Historiadores primitivos de las Indias occidentales que preparó Andrés González Barcia. Sobre la muerte de la amante de Cepeda cuenta Gómara que

[...] doña María Calderón, mujer de Hierónimo de Villegas, dijo que tarde o temprano se habrían de acabar los tiranos. Fue allá Caravajal [sic] y diole un garrote, y ahogola estando en la cama, por lo cual chistaron $\operatorname{todos}^{23}$.

Por otra parte, es sabido, como también observa Porras y una atenta lectura del texto lo confirma, que Garcilaso tuvo a la Historia ... de Gómara como fuente importante de información. En su Historia general del Perú (Segunda parte, Libro quinto, cap. XLII), el Inca Garcilaso narra el sangriento final de María Calderón:

Atrás, en su lugar, dijimos brevemente cómo Francisco de Carvajal dio garrote a Doña María Calderón y la colgó de una ventana de su posada. No dijimos entonces las palabras y razones que de una parte a otra se dijeron, por ir con la corriente de la historia y no ser aquél lugar de gracias. Ahora se pondrán las que allí faltaron ${ }^{24}$. Doña María Calderón, aunque estaba en poder de sus enemigos, hablaba muy al descubierto contra Gonzalo Pizarro y sus tiranías, y no era otra su plática ordinaria que decir mal dél. Carvajal, que lo supo, le envío amonestar una y dos y más veces que se dejase de aquellas gracias, que ni eran discretas ni provechosas para

22 Raúl Porras Barrenechea. Los cronistas del Perú (1528-1650). Lima, Sanmarti y Cía. Impresores, 1962, [p. 151].

23 Francisco López de Gómara. Historia general de las Indias y vida de Cortés. Caracas, Biblioteca Ayacucho, 1979, p. 268.

24 Garcilaso se refiere a lo mismo, aunque con menos detalle, en el Libro Quinto de la Segunda parte, capítulos XXVII y XVIII de su Historia general del Perú.

Bol. Acad. peru. leng. 56(56), 2013 
su salud. Lo mismo le dijeron otras personas, que temían su mal y daño. Doña María Calderón, en lugar de refrenarse y corregirse, habló de allí adelante con más libertad y desacato, de manera que obligó a Carvajal a ir a su posada para remediarlo, y le dijo: "¿Sabe vuesa merced, señora comadre (que cierto lo era), cómo vengo a darle garrote?”. Ella, usando sus donaires y pensando que Carvajal se burlaba de ella, respondió: "Vete con el diablo, loco borracho, que aunque sea burlando no lo quiero oir". Carvajal dijo: "No burlo, cierto, que para que vuesa merced no hable tanto y $\tan \mathrm{mal}$, vengo a que le aprieten la garganta; y para que vuesa merced lo crea, mando y requiero a estos soldados etíopes que le den garrote", que eran tres o cuatro negros que siempre traía consigo para semejantes hazañas. Los cuales la ahogaron luego y la colgaron de una ventana que salía a la calle. Carvajal, pasando por debajo della, alzó los ojos y le dijo: "Por vida de tal, señora comadre, que si vuesa merced no escarmienta de ésta, que no sé qué me haga”.

A principios del siglo XVII (1601-1625), Antonio de Herrera (1549-1625) publicó en ocho volúmenes su Historia general de los hechos de los castellanos en las islas y tierra firme del mar océano. La obra se presentó dividida en décadas, que es el nombre con el que después se le ha conocido. Esta obra fue reeditada en Amberes en 1728; y en Madrid entre 1725 y 1830. Herrera tampoco estuvo en el Perú pero pudo disponer de toda la documentación que existía sobre la conquista en el Archivo General de Indias. A partir de la edición de 1725-1730, la obra de Herrera circuló profusamente por Latinoamérica: no hay duda de que Segura la empleó al redactar Gonzalo Pizarro. Los siguientes textos ilustran lo dicho:

\section{Capítulo I}

(Versión de Herrera): [Dijo Cepeda] "No señor, pero es bien que esté firmada y pronunciada la sentencia para ejecutarla cuando los prendamos". Entonces Carbajal, dando grandes carcajadas, replicó: "A fe de buen soldado que yo entendía que firmando yo la sentencia había de caer un rayo y matarlos a todos juntos allá donde están \&\&\&"

(Versión de Segura): [Dijo Cepeda] "Nadie ha dicho tal, señor maese de campo — respondió el licenciado-, pero conviene que 
esté firmada y pronunciada para ejecutarla cuando los prendamos". / Aquí no pudo contenerse el maese de campo y prorrumpió en tan grande carcajada de risa que los que lo escuchaban no pudieron menos de amostazarse. / "iA fe de buen soldado! —exclamó después que se hubo repuesto_-, que yo me figuraba que estampar mi firma sobre ese papel y caer un rayo que convirtiese en polvo a todos esos caballeros, allá donde se hallan, había de ser una misma cosa".

\section{Capítulo VI}

(Versión de Herrera): "Señora comadre: Si de ésta no escarmienta vuesa merced, no sé qué me haga".

(Versión de Segura): “iPor vida de tal!, señora comadre que si vuesa merced no escarmienta de ésta, consiento que me rapen el cogote y me embaúlen en una ermita”.

Gran difusión alcanzaron las Décadas de Herrera pues refiriéndose a los años de la Conquista y las guerras civiles es frecuente encontrarlas citadas en el Diccionario histórico biográfico de Mendiburu.

Segura debe de haber utilizado fuentes adicionales para completar su obra y por ello resulta fácil encontrar los antecedentes de quienes participan en la fiesta que Carvajal ofrece en su casa en el Cuzco y que son mencionados por sus nombres (capítulo VI, primera parte): Catalina Leiton era la esposa de Carvajal; Bobadilla, Maldonado y Gonzalo de los Nidos se encuentran mencionados en todas las crónicas de esta sangrienta época. Todo esto parecería confirmar cuáles fueron las fuentes empleadas por Segura al preparar su Gonzalo Pizarro.

\section{Gonzalo Pizarro, ¿drama frustrado?}

Como se ha indicado antes, sostenemos, como tesis, que hacia 1839 o quizás uno o dos años antes, Segura redactó Gonzalo Pizarro como un drama histórico; sin embargo, al reparar en el limitado éxito (si es que en realidad lo obtuvo) que logró con sus otros dos dramas históricos preparados durante la misma época (Amor y política y Blasco Núñez de Vela), no se arriesgó a un tercer fracaso y decidió no montarlo sino, más bien, 
archivarlo entre otros papeles suyos (posiblemente junto con el drama $\mathrm{La}$ Pepa, redactado hacia 1834-1835). A principios de 1844, cuando habían transcurrido tres años sin que hubiera subido a los escenarios limeños alguna obra nueva suya (salvo sus comedias costumbristas El sargento Canuto, La saya y manto y La moza mala), recupera, reformula y publica Gonzalo Pizarro como novela-folletín.

Por esos tiempos y por las mismas razones también debe de haber refundido La espía, tal como lo indica Palma, según se comenta más adelante.

\section{Gonzalo Pizarro, puntos de contacto entre ambas versiones}

Ingresando al ámbito de lo conjetural, entre la novela conocida, el drama intuido y otras obras de Segura de aquellos años existen varios puntos en contacto que es necesario considerar.

Para empezar, Segura tiene antecedentes en la refundición de sus obras. Palma cuenta que La espía es refundición de "[...] una comedia antigua" 25 . Si se acepta que esta obra estrenada en 1845, es refundición de una comedia antigua, resultaría que bien podemos ubicar su redacción también en la serranía ayacuchana entre 1836 y 1839 lo que indicaría que los cuatro dramas históricos de Segura (incluyendo La Pepa) se redactaron entre 1834 y 1839 .

De $\tilde{N} a$ Catita existe una primera versión, hoy desconocida, en tres actos, de 1843-1844; y la que hoy se conoce, en cuatro actos, de 18551856. ¿Habría, pues, inconveniente en que Segura hubiera convertido una obra de teatro suya, como Gonzalo Pizarro, en novela?

La historia vinculó estrechamente a Blasco Núñez de Vela y a Gonzalo Pizarro, pues el Rey Carlos V nombra Virrey al primero y le encarga combatir y derrotar a Pizarro; pero Núñez de Vela fracasa, lo

25 Ricardo Palma, Prólogo a Manuel A. Segura, Teatro, p. VI. (Lima, Imprenta de la Juventud, 1858). 
que conduce a su ejecución por parte de las fuerzas enemigas. Que haya escogido como personajes centrales de sus primeros dramas a estos dos hombres, induce a pensar que la época atraía de manera especial a Segura y que este tenía acceso a las fuentes requeridas para preparar ambos dramas ${ }^{26}$. Más aún, no debería extrañar si en el desconocido drama Blasco Núñez de Vela hubieran aparecido entre sus personajes Gonzalo Pizarro o Francisco de Carbajal ni que el primero de ellos hubiera ordenado la ejecución del poco prudente primer virrey del Perú.

Desde una perspectiva formal, aparece una semejanza: Blasco Núñez de Vela está preparado en seis actos y Gonzalo Pizarro en seis capítulos. Son las únicas obras de Segura con este número de actos o capítulos.

\section{Propuesta de argumento para el drama}

Teniendo en cuenta el argumento ya conocido de la novela, hemos tratado de imaginar el posible argumento del drama:

\section{Acto primero}

La acción transcurre en Lima, en marzo de 1547, en una habitación de la casa de Diego Cepeda, ubicada en las inmediaciones de la Plaza de Armas, en el actual pasaje Olaya. La sala tiene cuando menos dos puertas, una que da a la calle y otra, más pequeña, que permanece cerrada.

Escena I. Personajes: Gonzalo Pizarro, Francisco de Carbajal y Diego Cepeda. Cepeda trata infructuosamente de convencer a Carbajal de que firme la sentencia que condena a muerte al "pacificador" Gasca

26 La bibliografía fundamental para los dos personajes es la misma: las Décadas de Antonio de Herrera (1549-1625), publicadas entre 1601 y 1615 y reeditadas en Amberes en 1728 y en Madrid entre 1725 y 1730; la Historia general de las Indias de Francisco López de Gómara (1511-1560), publicada en 1562 y reeditada por Andrés González Barcia en su colección de Historiadores primitivos de Indias occidentales en 1749; la Historia general del Perú del Inca Garcilaso de la Vega (1539-1616) que desde mediados del siglo XVIII circulaba profusamente en el Perú; y la Historia del descubrimiento y conquista del Perú de Agustín de Zárate (1514-?) publicada en 1555 y reeditada también por González Barcia en 1749.

Bol. Acad. peru. leng. 56(56), 2013 
y a sus seguidores, que representaban la causa de la autoridad real. Finalmente, Pizarro y Carbajal se retiran.

Escena II. Personaje: Cepeda. Cepeda permanece solo pensando en lo que podía hacer para liberarse de Carbajal y poder entregar a Pizarro al "pacificador" Gasca.

\section{Acto segundo}

El mismo escenario, a continuación de la escena anterior.

Escena I. Personajes: Cepeda y su amante, María Calderón, que babía escuchado tras una puerta el diálogo de la escena anterior. Ambos personajes conversan sobre lo que deberían hacer para destruir a Pizarro. Para salvarse, acuerdan enviar a Hernán Calderón, hermano de María, para que informe directamente a Gasca que ambos eran fieles a la causa del Rey y que solo esperaban la oportunidad para entregar a Pizarro.

Escena II. Personajes: Cepeda, María Calderón y el hermano de esta, Hernán. Cepeda y María convencen a Hernán para que viaje y trate de ubicar a Gasca, quien se encontraba en el norte del país, y le asegure que ambos eran leales al Rey y que solo esperaban el momento oportuno para traicionar a Pizarro y a Carbajal y entregárselos. Hernán acepta el encargo. Los hermanos Calderón se retiran juntos a su domicilio; por la puerta pequeña, Cepeda se dirige al interior de la casa.

\section{Acto tercero}

Campamento de Gonzalo Pizarro en La Legua, lugar ubicado a mitad de camino entre Lima y el Callao. La escena tiene lugar dos días después de lo referido en el acto anterior.

Escena I. Personajes: Pizarro, Hernán Calderón y quienes habian capturado a este, otros capitanes y soldados. Mientras Pizarro se encontraba despachando, llevan ante él a Hernán Calderón, que había sido capturado por una partida pizarrista cuando se dirigía al norte en 
busca de Gasca. Pizarro, sin reconocerlo, ordena que lo entreguen a Carbajal para que sea ejecutado.

Escena II. Personajes: Pizarro, María Calderón y otros capitanes y soldados. Entra María Calderón, quien ha forzado su ingreso; postrándose ante Pizarro, su antiguo amante, le ruega por la vida de su hermano. Siendo inútiles todos sus argumentos, invoca a la Virgen Santísima sabiendo la devoción que por ella tenía Gonzalo; ante esta invocación, Pizarro acepta perdonar a Hernán.

\section{Acto cuarto}

Campamento de Gonzalo Pizarro en La Legua.

Escena $\mathbf{I}^{27}$. Personajes: Pizarro, Cepeda. Cepeda, enterado de que Hernán Calderón, a quien Pizarro acababa de perdonar, había logrado huir en forma exitosa, vuelve a aparecer en el campamento de Pizarro y continúa intrigando de manera infatigable con el afán de desprestigiar a Carbajal.

Escena II ${ }^{28}$. Personajes: Carbajal, cuatro soldados negros que siempre lo acompañaban, María Calderón. Carbajal, al enterarse de que Hernán Calderón había huido, se dirige a Lima sospechando que se encontraba en casa de su hermana, lugar que acababa de abandonar. Mientras dura la búsqueda, Carbajal increpa a María por su comportamiento, en medio de un debate sumamente tenso.

27 Esta escena es irrelevante y repetitiva. Dentro del eventual drama Gonzalo Pizarro, Segura pudo haber prescindido de ella sin la menor dificultad en cuyo caso el Capítulo cuarto hubiera estado conformado por solo una escena, la que en la versión novela es la que sigue (Capítulo cuarto, escena II). La extensión del diálogo entre Gonzalo y Cepeda hace en la versión novela que esta sea una de las escenas más extensas.

28 Dentro del drama Gonzalo Pizarro, si es que confirmando nuestra tesis este realmente existió, esta escena debe de haber tenido una extensión mayor pues iba preparando la trama hasta llegar al final de la obra que se produce en la escena I del Capítulo sexto.

Bol. Acad. peru. leng. 56(56), 2013 


\section{Acto quinto}

El escenario es el Cuzco, cinco meses después de los hechos ocurridos en los primeros cuatro actos ('iagosto? de 1547), en la casa que ocupaba Cepeda.

Escena I. Personajes: Cepeda, María Calderón. Pese a que Gasca les había confirmado por escrito que estaba debidamente informado de su lealtad al Rey, Cepeda y María conversan preocupados porque el "pacificador" Gasca y sus tropas aún no llegan al Cuzco.

Escena II. Personajes: Pizarro, Cepeda, María Calderón. Gonzalo Pizarro irrumpe y encara enérgicamente a María que continúa desprestigiándolo. Después de que él le hace presente que sería su última advertencia, ella da a entender que no le concede importancia a la misma. Pizarro se retira violentamente en medio del temor y la desesperación de Cepeda.

\section{Acto sexto}

Las acciones transcurren en el Cuzco, inmediatamente después del acto anterior, en casa de María Calderón.

Escena I. Personajes: Carbajal, María Calderón, dos de los soldados negros que acompañaban a Carbajal. Carbajal, enterado del violento cambio de palabras sostenido entre Gonzalo Pizarro y María Calderón, decide motu proprio intervenir. Acompañado de dos de los soldados etíopes que lo protegían, ingresa a la casa de María. Le comunica a Calderón que se le va a aplicar la pena del garrote lo que los negros hacen de inmediato en medio de los pedidos de clemencia de la altanera mujer. Cumplido su propósito, los negros acatan la orden de Carbajal de colgar el cadáver de una ventana para que sirva de escarmiento; luego de este hecho, la siniestra comisión se retira. Para resaltar lo execrable de la ejecución, podría haberse utilizado la frase del cronista Herrera: "Señora comadre, si de esta no escarmienta vuesa merced, no sé qué me haga” ${ }^{29}$.

29 Manuel de Mendiburu. Diccionario histórico biográfico del Perú. Tomo segundo. Lima, Imprenta de J. Francisco Solís, 1876, p. 120. 
Escena II. Personajes: Carbajal, Cepeda. En momentos en que Carbajal y los soldados se retiran, llega Cepeda a quien Carbajal señala el cadáver de María colgado. El drama bien podía terminar con la frase de Carbajal a Cepeda que Segura emplea en la novela: “¿No le dije a vuesamerced que mi comadre era una santa? Mírela vuesamerced, qué calladita está. Apuesto ciento contra uno que no vuelve a abrir el pico".

\section{Surge la novela}

A principios de 1844 —quizás desde las últimas semanas del año anterior- Segura ya había abandonado su actividad como autor de cuadros de costumbres y poeta, se había separado de la Guardia Nacional y no tenía una relación estable con el periodismo. Es posible que por entonces Segura mirara hacia atrás, retomara su postergado drama Gonzalo Pizarro y los seis actos que lo componían, lo convirtiera en una novela-folletín conformada por un número igual de capítulos y lo entregara a la imprenta para deleite de los por entonces suscriptores de El Comercio.

¿Qué razones pudieron haber movido a Segura a dar forma de novela a su drama primitivo si esto es, tal como sostenemos, lo que realmente sucedió? Creemos que solo hay dos posibilidades: la primera es la desilusión que pudo haberle causado el fracaso consecutivo de dos de sus obras de carácter histórico para teatro: Amor y política y Blasco Núñez de Vela (el primer fracaso databa de septiembre de 1839; el segundo, de enero de 1840 , solo tres meses y medio después). Esto es lo que creemos que aconteció realmente. La otra posibilidad puede haber sido beneficiarse con algún estipendio ofrecido por los directivos de $E l$ Comercio. No puede descartarse la ocurrencia simultánea de ambas posibilidades. Este es un asunto que queda por develar en la historia de una obra que sin duda es la primera novela histórica de nuestra vida republicana pero de la cual nadie se preocupó durante ciento sesenta años. 


\section{Manuel Ascensio Segura y la aparición de la novela en el Perú republicano}

Queda por dilucidar la antigüedad de Gonzalo Pizarro entre las novelas con que se inicia este género en el Perú republicano. A partir de 1969, cuando apareció la primera y valiosa bibliografía de la novela peruana ${ }^{30}$, se consideró que las primeras dos novelas del Perú republicano eran $E l$ bijo del crimen, de Julián del Portillo ${ }^{31}$, y la ya citada El padre Horán, de Aréstegui, que datan de 1848. El semanario limeño El Talismán (Lima, 1846-1847), que por entonces dirigía el poeta español Fernando Velarde, proporciona información adicional: refiere que en septiembre de 1846 acababa de aparecer - y recomienda su lectura — Los amores de un marino, del esforzado Julián M. del Portillo; ${ }^{32}$ en el mes siguiente inicia la publicación, que tomará siete números consecutivos, de una novela-folletín del mismo autor: Amor y muerte. Esta información remonta en dos años la fecha que ahora interesa establecer. La aparición de Gonzalo Pizarro como novela-folletín atrasa esa fecha en otros dos años más, hasta 1844.

Sin embargo, desde los últimos años de la década de 1830 ya habían aparecido en el Perú las primeras manifestaciones de prosa de ficción, dos de las cuales publica en forma de folletín El Comercio ${ }^{33}$. Velásquez, al estudiar el asunto, juzga que Lima de aquí a cien años, de Portillo, "[...] es quizás el primer texto narrativo ficcional plenamente original escrito por un peruano que se publica por entregas en un periódico". Sin embargo, ponderando bien la situación, Velásquez apunta:

\footnotetext{
30 Elsa Villanueva. Op. cit., p. 57.

31 Julián M. del Portillo. El hijo del crimen; novela peruana. Lima, Imp. de José M. Masías, 1848.

32 De Los amores de un marino se da cuenta en el N. ${ }^{\circ} 22$, de 27 de septiembre; Amor y muerte se reproduce en siete números consecutivos, entre el 11 de octubre y el 22 de noviembre de 1846. De Los amores de un marino comenta la redacción: "Hemos leído esta linda novelita que acaba de publicar el apreciable joven D. Julián M. Portillo. Nos parece bien escrita y digna de figurar en el tocador de nuestras suscriptoras...".

33 Es posible que se trate de las primeras dos obras en prosa escritas por el infatigable Julián M. del Portillo: El Inventario, publicado como folletín en tres números $(1040,1041 \mathrm{y}$ 1042) de El Comercio (Lima, 1843); y Lima de aquí a cien años, aparecido, también como folletín, en cuatro números (1213, 1216, 1241 y 1242) de El Comercio, (Lima, 1843), (Marcel Velásquez. Op. cit., pp.16-36).
} 
[...] aunque [en Lima de aquí a cien años] podemos encontrar incipientes elementos propios de la novela de folletín (manejo del suspenso en función de las unidades de las entregas, conciencia social, intervención de la Providencia para solucionar los conflictos y fin pragmático de carácter político), esta narración escapa a los marcos tradicionales de la novela de folletín porque no existe la lógica argumental (despojorecuperación-reconocimiento) ni la lucha esquemática entre el Bien y el Mal representados por personajes ${ }^{34}$.

Mientras tanto, distinta es la situación de Gonzalo Pizarro, publicada nueve meses después: está dividida en forma equilibrada en seis capítulos, duplica en extensión a los dos textos de Portillo, ofrece un argumento de una razonable solidez, la tensión de la cual la trama está dotada se incrementa en forma gradual, los personajes aparecen bien perfilados, muchos de los diálogos que aparecen dan testimonio de destreza literaria, proporciona emotividad a la narración cuando describe la forma en que María Calderón implora a Pizarro por la vida de su hermano y cómplice, posee un final de un dramatismo impresionante.

Restringidos por Velásquez en forma tan significativa los méritos literarios de Lima de aquí a cien años, es posible, pues, que a la historia de la novela en el Perú republicano pueda darse comienzo con Gonzalo Pizarro, lo que conferiría a don Manuel Ascensio Segura un nuevo reconocimiento que nunca hubiera esperado.

\section{Correspondencia:}

Alberto Varillas Montenegro

Miembro de la Academia Peruana de la Lengua.

Correo electrónico: varillas.alberto@gmail.com

34 Marcel Velásquez. Op. cit., p. 32.

Bol. Acad. peru. leng. 56(56), 2013 